\title{
Consumo y construcción de redes: migrantes venezolanos en la ciudad de Bogotá
}

\section{Consumption and network construction: Venezuelan migrants in Bogotá city}

\section{César Augusto González Vélez iD}

Universidad Central, Colombia

cgonzalezv2@ucentral.edu.co

\section{Fabio Andrés Medina Ostos iD}

Universidad Central Colombia

fmedinao@ucentral.edu.co

\begin{abstract}
Resumen
Este artículo presenta algunos resultados de la investigación "La ruta del tequeño. Identificación e integración de las y los migrantes venezolanos en Bogotá a través de los espacios de consumo". El estudio buscaba comprender la producción social de los espacios de consumo relacionados con las y los migrantes venezolanos en Bogotá. En este artículo, en particular, abordaremos la relación entre el consumo y la construcción de redes, aproximándonos a la manera como a través del envio de remesas de Colombia a Venezuela, así como por medio de los grupos de Facebook y del intercambio de productos alimenticios, los migrantes venezolanos fortalecen redes migratorias que les ayudan a enfrentar el proceso de integración a la vida urbana. En términos metodológicos, la investigación muestra la aplicación de la observación etnográfica, la encuesta y los grupos de discusión virtuales.
\end{abstract}

Palabras clave: migración, consumo, redes sociales, integración social.

\begin{abstract}
This article presents some results of the research "The Tequeño Path. Identification and integration of Venezuelan migrants in Bogotá through consumption spaces". The study sought to understand the social production of consumption spaces related to Venezuelan migrants in Bogotá. In this article, in particular, the relationship between consumption and the construction of networks is presented, approaching the way in which through the sending of remittances from Colombia to Venezuela, as well as through Facebook groups and the exchange of food products, Venezuelan migrants strengthen migratory networks that help them face the process of integration into urban life. As for methodology, the research shows the application of netnographic observation, surveys, and virtual discussion groups.
\end{abstract}

Keywords: Migration, Consumption, Social Networks, Social Integration.

Articulo: Recibido el 12 de agosto de 2021 y aprobado el 23 de octubre de 2021

\section{Cómo citar este artículo:}

González Vélez, C. \& Medina F. (2021). Consumo y construcción de redes: migrantes venezolanos en la ciudad de Bogotá. Reflexión politica 23(48), pp. 11-24 doi: https://doi.org/10.29375/01240781.4218.

\section{Introducción}

Este artículo presenta algunos resultados de la investigación "La ruta del tequeño. Identificación e integración de las y los migrantes venezolanos en Bogotá a través de los espacios de consumo”, financiada por la octava convocatoria interna de investigación de la Universidad Central. Esta investigación se proyectó como una etnografía sobre la producción social de los espacios de consumo de las y los migrantes; no 
obstante, dadas las dificultades que nos planteó la pandemia en el año 2020, optamos por hacer una adecuación metodológica que nos llevó hacia un enfoque de etnografía digital. Más adelante explicaremos con más detalle de qué manera desarrollamos esta transición.

En este apartado introductorio es necesario señalar que el énfasis que se hizo en el consumo representó un abordaje alternativo al interior de los estudios de la migración, que tradicionalmente han dado un peso mayor a la producción como una categoría y escenario central para comprender la integración de las y los migrantes al contexto de acogida. De acuerdo con Berganza y Solórzano (2019), la integración, más que un asunto cuantitativo es una cuestión cualitativa, que se expresa cuando en la cotidianidad de las y los migrantes se logra la experiencia de ser parte del mundo que se habita materialmente. En ello, la posibilidad de consumir ciertos productos, algunos con cierta carga identitaria, es un proceso que adquiere relevancia y que en algunas investigaciones se da por sentado como un efecto de la inserción al mercado laboral. Este artículo presenta un análisis sobre el lugar que las prácticas de consumo ocupan en el proceso de integración de las y los migrantes venezolanos a la ciudad de Bogotá, y en particular, en la construcción de redes entre migrantes.

La lógica de la exposición que seguiremos será la siguiente: en primera medida presentaremos un panorama teórico general sobre los debates que enmarcaron la realización del trabajo, luego presentaremos los aspectos metodológicos del estudio y su transformación dada la coyuntura de la pandemia. Una vez hayamos construido este marco, ofreceremos un breve contexto de la dimensión urbana de la migración venezolana en Bogotá, para luego presentar los hallazgos en torno a la relación entre consumo y construcción de redes sociales, mostrando cómo en el envío de remesas, en la venta de productos alimenticios y en los grupos de Facebook, se fortalecen las redes entre migrantes. Todo esto a partir de las posibilidades de interacción que permite la tecnología.

\section{Coordenadas teóricas}

El estudio propone un punto de encuentro entre los estudios sociales del consumo y los estudios sobre las migraciones. En lo concerniente a los estudios sociales del consumo es fácil reconocer que existen en su interior diferentes miradas y aproximaciones teóricas y metodológicas (Montenegro y García, 2021; González, 2021). Aquí nos situamos en una posición que considera que consumir va más allá de la compra, o dicho de otra forma, que se trata de un proceso social complejo que sucede en el marco de unas relaciones politicas que definen, entre otras cosas, la disponibilidad de los productos; de unas relaciones sociales que dan cuenta de la manera en que nos encontramos y desencontramos en (para y desde) el consumo; de unas relaciones culturales, entendidas como las relaciones que dan sentido, valor simbólico a lo que consumimos; y de unas relaciones económicas, que nos remiten a los intercambios y la producción y circulación de valor que tiene lugar en las prácticas de consumo. Estas distinciones por supuesto son simplemente de carácter analítico y solo buscan ilustrar al consumo como un fenómeno multidimensional.

Como señala Narotsky (2004), abordar el consumo implica superar la postura de un sector de la ciencia económica clásica que considera que consumir es un epifenómeno de la producción, o, dicho de otra forma, el final del ciclo económico. De la misma manera (también sobre esto llama la atención Narotzky), comprender el consumo nos debe permitir ir más allá de una posición culturalista, que vea en el consumo solo un intercambio de signos y no un proceso que está también determinado materialmente. En suma, abordar el consumo desde una perspectiva social implica reconocer la dialéctica entre consumir y producir, entre lo material y lo simbólico, y entre el valor de cambio, el valor de uso y el valor signo.

Esta densidad del consumo nos permite encontrar en sus prácticas una relación con diferentes procesos sociales. En el consumo se expresa la construcción social de lo deseable, se movilizan formas de identificación y procesos de subjetivación, así como se definen los estilos de vida y las condiciones mínimas que indican que las personas pueden participar (de maneras desiguales, por supuesto) de los 
recursos disponibles en los diferentes contextos socioculturales que habitan.

Por ello, consideramos que abordar la migración desde la perspectiva social de los estudios del consumo nos permite trazar algunos cuestionamientos interesantes. ¿Qué lugar ocupa la posibilidad de consumir (que no es exactamente igual a la de trabajar) en la decisión de las y los migrantes de movilizarse del contexto emisor al contexto de acogida? ¿Cómo influyen las prácticas de consumo nostálgico en los procesos de subjetivación de las y los migrantes? ¿Cómo interviene la tecnología en la construcción de redes de migrantes en torno al intercambio de productos asociados a la identidad de origen? ¿Cómo se construyen nuevos mercados para las y los migrantes en los contextos de acogida? ¿Estas redes de intercambios de y para migrantes pueden desbordar las lógicas de lo nacional y construir relaciones económicas y culturales transnacionales? Estas son algunas preguntas que aparecieron en el desarrollo del proyecto y que fueron dando forma al diálogo entre los estudios sociales del consumo y los estudios sobre las migraciones.

Los procesos migratorios son fenómenos históricamente situados que se desarrollan con ciertos matices particulares. A lo largo de la historia humana, las migraciones han dado forma a las sociedades y han cambiado el rumbo de los pueblos. No es el objeto de este artículo hacer un estado del arte de los estudios de las migraciones, solo señalaremos algunos debates que son importantes para enmarcar el análisis que presentaremos más adelante sobre el caso en cuestión. En primera medida, aparece el tema de la integración que genera diferentes posturas. Para Berganza y Solórzano (2019): “diversos autores (Blanco, 2002; Gómez Crespo, Barbosa Rodríguez, López-Caniego y Martínez Aranda, 2005) señalan que, a pesar de no ser un tema nuevo, ha sido poco el trabajo conceptual sobre la integración de migrantes" (p. 84).

De otro lado, Torres Matus (2012) llama la atención sobre la poca claridad y consenso que existe en torno al concepto de integración y sugiere que en el caso de los migrantes "La definición de lo que es integración determina las políticas públicas, el tratamiento académico y la opinión pública" (Torres Matus, 2012, p. 220). La integración como política de gobierno adquiere matices diferentes en los distintos países. La integración como experiencia involucra otros elementos en los que tiene lugar lo político y lo jurídico, pero también lo emocional, el disfrute y la seguridad ontológica de las y los migrantes, lo que pasa, entre otras cosas, por la posibilidad de consumir. Así, pensar la integración no es una tarea que termine cuando se corrobora la existencia formal de ciertos derechos para una población que busca integrarse. La integración es un proceso complejo que sucede a nivel macro como política y que se vive a nivel micro como experiencia, como estrategia personal.

Resulta muy interesante para nosotros lo que plantea Torres Matus (2012): ”(..) el migrante no es ciudadano pleno, pero al ser consumidor de bienes, servicios e ideas, el consumo le permite una vía de inclusión identitaria de mercado o posmoderna” (p. 213). La integración vía Estado se materializa en la existencia y posibilidad de ejercicio de algunos derechos; mientras que la integración vía mercado implica ser tomado en cuenta como consumidor de bienes, servicios e ideas, así como tener la posibilidad material de participar en estos intercambios. La distinción entre estos dos planos es simplemente analítica, dado que los dos están intimamente ligados.

Estamos de acuerdo con que: "la integración no puede darse de forma individual, es un proceso colectivo que no debe ignorar la identidad cultural de las comunidades de inmigrantes" (Berganza y Solórzano, 2019, p. 87). Esta integración colectiva no puede simplemente medirse con coberturas o fiebres de regulación transitoria; la integración es un proceso de larga duración y de tensiones sociales que se expresan también en la cultura.

Un cierto lastre estructural funcionalista podría reducir la integración social a la inclusión de las personas al subsistema económico. Por supuesto, el lugar que las y los migrantes ocupan en el sistema productivo perpetúa las inequidades $\mathrm{y}$ fortalece procesos de exclusión, xenofobia y degradación. Sin embargo, esto no implica que obtener un trabajo sea, en sí, estar incluido en la vida social, menos en un país como Colombia en donde la informalidad, según el DANE, asciende al 48,6\%; el consumo y disfrute de los bienes y servicios de una sociedad puede ser también, desde la experiencia de la gente, un indicador de inclusión (Torres Matus, 2012).

Otra discusión importante dentro de los estudios de migración es la relacionada con la adaptación y la transmigración. Como señala 
Carmen Caamaño (2010), es necesario considerar el lugar de la simultaneidad en los procesos de migración; esto no significa otra cosa que comprender cómo a través de las y los migrantes se mantienen relaciones entre los contextos de origen y los contextos de recepción, relaciones que dan cuenta de dinámicas transmigratorias. Las posibilidades tecnológicas para desarrollar nuestra interacción más allá de lo local hacen que se potencien las redes migrantes y sea posible que las y los agentes mantengan relaciones con las instituciones, los grupos de pares y en general con las redes sociales que perviven en su contexto de origen (Levitt y Gilk, 2004).

Esto no quiere decir que pensar en la integración sea una empresa baldía. Como ya se señaló, esta adaptación, en muchos casos, coexiste con el mantenimiento de relaciones transnacionales, en las que las y los migrantes mantienen vida significativa, de manera simultánea, entre el allá y el acá. Lo que está en el fondo es la necesidad de superar el nacionalismo metodológico (Levitt y Gilk, 2004) y considerar las relaciones sociales que establecen muchos migrantes más allá de las limitaciones espacio-temporales de la interacción cara a cara.

Recogemos las conclusiones a las que llega Portes (2005), un autor que ha abordado a profundidad las relaciones que los migrantes establecen más allá de las fronteras nacionales. El autor señala que: 1. El transnacionalismo representa una perspectiva novedosa, pero no un fenómeno nuevo; 2. El transnacionalismo es un fenómeno de la migración desde abajo, no es un asunto burocrático de misiones internacionales o de disposiciones institucionales; 3 . No todos los migrantes son transmigrantes. Algunos habitan las relaciones transnacionales, pero otros pierden en buena medida la simultaneidad que supone la transmigración; 4. El transnacionalismo inmigrante tiene sus consecuencias macrosociales. Si bien es un fenómeno desde abajo, las prácticas que genera la transmigración tienen un impacto global a nivel económico y político; y 5. El grado y las formas de activismo transnacional varían según los contextos de salida y recepción. Personas que emigran de contextos rurales, sin un entrenamiento previo en las tecnologías de la comunicación, podrían tener menos activismo transnacional, mientras que migrantes de la ciudad que han tenido experiencia en viajes y en mantenimiento de relaciones más allá del mantenimiento del mismo contexto espaciotemporal, podrían perpetuar de manera más eficaz relaciones transnacionales. Estas pistas de Porter matizan el fenómeno que queremos abordar y nos dan luces sobre cómo comprender a los migrantes venezolanos en Bogotá, pues lo que encontramos en la indagación empírica es que muchos venezolanos residentes en Colombia siguen teniendo relaciones significativas (a nivel económico, cultural, político, social) con su país de origen, lo que describe una dinámica transnacional en el sentido ya presentado. Uno de los aspectos en los que pueden evidenciarse estas relaciones transnacionales es el consumo.

Autores como Itzigsohn et al (1999), Portes (2005), Levitt y Gilk (2004), entre otros, han señalado hace ya un buen tiempo la pertinencia de implementar el enfoque transnacional en el abordaje de la migración, y además, han puesto de manifiesto que si bien este enfoque representa un avance en las ciencias sociales, el establecimiento de dinámicas de las y los migrantes más allá de las barreras de lo nacional no es algo nuevo. Aun así, las prácticas y redes transnacionales se difuminan en las representaciones que tenemos sobre la migración y las y los migrantes, a quienes seguimos considerando como cuerpos extraños que buscan dejar atrás sus contextos de origen e incluirse en los contextos de recepción.

Un concepto fundamental, dentro de los estudios sobre migración, es el concepto de redes migratorias (Pedone, 2005). Este nos sitúa en un abordaje plenamente sociológico de la migración, como un proceso que da forma a las relaciones sociales y potencia, de manera diferente, la existencia de capitales sociales. Como señala Zenteno (2000), las redes sociales, no necesariamente atadas a las relaciones de parentesco, se convierten en amortiguadores de la llegada de los y las migrantes, creando unas condiciones sociales que aminoran el efecto hostil de pasar de un contexto social a otro. Las redes median la entrada al mercado laboral, ponen en circulación conocimientos sobre las prácticas locales, caminos para conectar el aquí y el allá, y hacen posibles formas de consumo nostálgico, así como también pueden influir en la decisión de muchas personas que podrían salir de su contexto de origen de manera más tranquila si saben, o creen saber, que una red de apoyo los estará esperando en el nuevo contexto; todo esto reduce los costos 
y mitiga los riesgos de la migración internacional (Massey y Parrado, 1997; Gómez, 2010).

Si bien los y las migrantes habitan redes sociales que tienen, en muchos casos, dinámicas transnacionales, también es cierto que participan de otros tipos de relaciones en el contexto de recepción y que su socialización puede imbricar la pertenencia a diferentes grupos (y redes), que no están constituidos exclusivamente por migrantes. Esto para no "esencializar" el proceso y no perder de vista la existencia de múltiples formas de relacionamiento y de integración social al interior de procesos migratorios.

Por último, es necesario dejar por lo menos enunciada la importancia de la interseccionalidad para pensar la relación entre migración y consumo, que hemos venido trabajando a lo largo del texto. La interseccionalidad ha puesto de manifiesto falsos universalismos $\mathrm{y}$ ha evidenciado cómo ciertas categorías como género, etnicidad y clase, entre otras, determinan la experiencia de la migración: "Los estudios sobre migraciones y trabajo tienen por delante la tarea de explicar en profundidad cómo la intersección de clasificaciones sociales produce y reproduce formas de explotación laboral que se traducen en desigualdades sociales" (Anthias, 2006, p. 707).

En lo que respecta al consumo, categorías como género, etnicidad y clase, también son fundamentales para conocer las diferentes maneras en las que se construye valor y significado, asî como los procesos que reproducen desigualdades y violencias. En el trabajo empírico que se presentará más adelante fue una categoría residual, en cuanto no se hizo un análisis diferenciado de acuerdo con la clase social, el género, etc.; no obstante, esta falencia puede ser la base para futuros procesos de investigación y la señalamos para poder marcar algunos intereses que podrían generar una agenda de investigación en el futuro, considerando la relación entre consumo y migración desde la perspectiva de la interseccionalidad.

\section{Contexto general de la migración venezolana en Colombia}

La migración que nos ocupa no se da como un proceso espontáneo o aspiracional. De acuerdo con Blouin (2019), se trata de una migración forzada. La crisis humanitaria de Venezuela ha ocasionado un éxodo masivo (Gandini, Lozano y Prieto, 2019). Así, la migración venezolana de las dos últimas décadas está antecedida por una fractura en el Estado venezolano; esto le da un carácter particular al proceso, ya que la decisión de migrar, la activación de las redes migratorias, las rutas y flujos por los que atraviesan los migrantes, están determinados por el volumen de gente que se desplaza, por la informalidad de algunas rutas y por las disposiciones especiales que se adoptan en los contextos de acogida.

Los datos recabados por Blouin (2019), que no son otros que los producidos por los gobiernos de la región, muestran que Colombia es el país que más migrantes venezolanos ha recibido (1.825.000 para 2020), seguido de Perú (1,043.000 para 2020) y de Ecuador (415.835 para 2021).

Colombia y Venezuela han sido países de alto tránsito de migrantes por su proximidad geográfica y su historia compartida. En los periodos de abundancia de Venezuela, millones de inmigrantes de diferentes partes del mundo llegaron a sus tierras; en ese marco, entre 1970 y 1985 se registraron alrededor de cinco millones de personas de origen colombiano en ese país. En la actualidad, según Migración Colombia, más de 1.825.000 venezolanos se han asentado en el territorio nacional. La pandemia del COVID-19 devino en que muchos venezolanos regresaran a sus contextos de origen, para luego, cuando se flexibilizaron las medidas, regresar una vez más a las ciudades colombianas.

La ciudad de Bogotá ha albergado 352.431 venezolanos, es decir, cerca de la quinta parte de las y los migrantes que residen en el país. Dado que es la capital, muchas personas ven en Bogotá un lugar para asentarse y estabilizarse económicamente. Según el DANE, en el 2020 en esta ciudad el desempleo estaba en el 18,2\%, en comparación al país que en general tuvo una tasa de $15.9 \%$. Ciudades capitales como Medellín tuvieron un $19 \%$ en dicho periodo y en Cúcuta, una ciudad de frontera entre los dos países, se llegó hasta un $24.6 \%$ de desempleo en el tercer trimestre de dicho año. Todo esto para indicar que Bogotá es, tanto a nivel estadístico como a nivel del imaginario colectivo colombiano, "una ciudad de oportunidades".

En muchos procesos de migración, es notoria la manera en que se crean colonias, o guetos. Los barrios chinos en diferentes países del mundo serían un ejemplo evidente de tal fenómeno. En el caso de la migración venezolana a Bogotá, la 
cual ya es un tema de importancia en la agenda urbana, no se han evidenciado concentraciones con esas características que puedan dar cuenta de un gueto propiamente dicho. El barrio Cedritos, un sector de clase media alta bogotana, ha albergado un sector de las y los migrantes que llegó a la ciudad con los suficientes recursos para instalarse allí. Esto ha devenido en que se nomine al barrio como "Cedrizuela". No obstante, no es claro que exista una territorialización excluyente con los locales o que cree una dinámica social, económica y cultural que permita afirmar que se trata de un gueto. Además, como se notará en el mapa que elaboró el equipo y que se presentará a continuación (Figura 1), dicho barrio, ubicado en la localidad de Usaquén, no concentra una representación porcentual que indique que la mayoría de las y los migrantes tienen como centro a "Cedrizuela", por lo que consideramos que el fenómeno en términos urbanos, de la migración venezolana a Bogotá, puede explicarse de otra forma.

Figura 1. Cantidad de migrantes venezolanos que viven en Bogotá

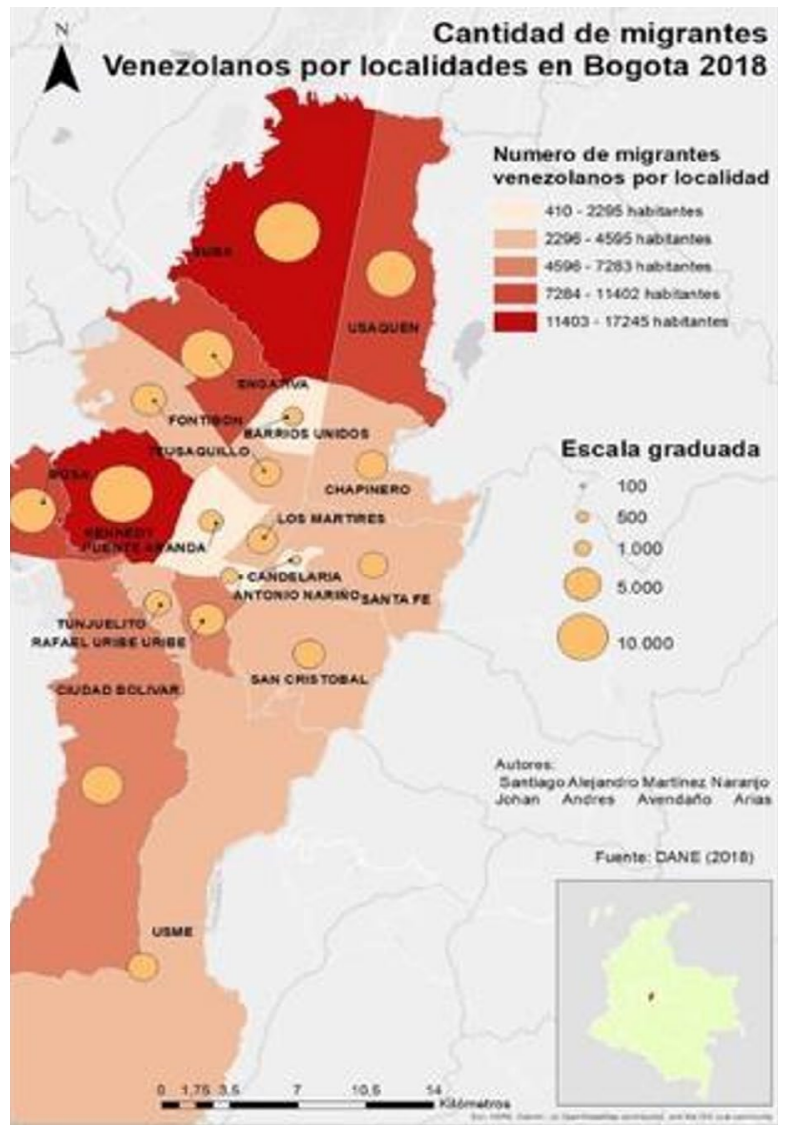

Fuente: Elaboración propia a partir de Migración Colombia y DANE (2018).
La población migrante venezolana en Bogotá se ha ubica, en mayor medida, en lo que se conoce como la medialuna occidental (Figura 1): Suba (17.245), Kennedy (15.101), Engativá (11.402), Usaquén (9.674) y Bosa (9.236). Lo que se puede concluir es que la población se asentó en las localidades más densamente pobladas a lo largo y ancho del territorio. Es decir, que hasta el momento no se ha dado una única concentración notable que pueda indicar que hay un territorio exclusivo de migrantes, sino que la tendencia parece indicar que el fenómeno se diluye en diferentes contextos urbanos. Esto debe leerse, además, a la luz de lo que se mencionaba al principio de este acápite: los dos países tienen unos referentes y prácticas culturales que no son iguales, pero que podrían favorecer un proceso de sincretismo. Es muy pronto para saber cómo evolucionará el fenómeno, pero por ahora es posible afirmar que existen diversos procesos paralelos de posicionamiento de las y los migrantes en la vida urbana de Bogotá, todos de acuerdo a diferentes contextos territoriales y a diferentes campos sociales. No obstante, es importante señalar que los datos (Figura 1), también señalan que las y los migrantes han venido ubicándose en mayor medida en escenarios en donde la cobertura de servicios sociales y las oportunidades económicas son insuficientes.

En línea con Gandini et al. (2019), es importante situar cómo ha sido la intervención del gobierno de Colombia, en comparación con los países de la región, en lo que respecta a la migración venezolana, lo que nos permite pensar el proceso de integración de las y los migrantes que le da sentido a los datos empíricos que presentaremos más adelante. Estos autores comparan los gobiernos que más población venezolana han recibido en diferentes aspectos: 1. La gratuidad del proceso de regularización de los migrantes; 2. Los derechos que adquieren los migrantes; 3. La atención a personas que entraron al país de manera irregular; 4. Los requisitos que se han solicitado los migrantes para obtener la condición de refugiados; y 5. La adaptación en el tiempo a los cambios en el proceso migratorio.

Antes de seguir, es imprescindible aclarar que no se podría afirmar que las medidas tomadas por el gobierno nacional de Colombia podrian llevarnos a concluir que hay una integración efectiva de los migrantes venezolanos a la vida del país. No obstante, en función de la comparación 
realizada por Gandini et al (2019), se señala cómo: (1) en Colombia, en relación con otros países como Chile y Perú, el permiso especial de permanencia es un documento gratuito. Así mismo, (2) mientras en Perú las y los migrantes solo tienen derecho al trabajo, en Colombia tienen derecho a la educación, la salud y el trabajo, de acuerdo con las disposiciones oficiales. Aquí es pertinente aclarar que el acceso a la educación tiene limitaciones en Colombia, en particular para la población irregular, así como la salud, que se restringe en buena medida a la atención por urgencias. En el caso del trabajo también hay restricciones consagradas en la Constitución. Técnicamente no hay un permiso de trabajo, pero con los papeles que acreditan a un migrante como regular (el Permiso Especial de Permanencia -PEP-) puede ejercer ciertas labores bajo formas de contratación legal; no obstante, no puede, por ejemplo, afiliarse a una Aseguradora de Riesgos Laborales.

Además, (3) Colombia permitió que algunas personas (un número limitado de migrantes) que entraron de manera irregular, pudieran normalizar su situación a través del RAMV (Registro Administrativo de Migrantes Venezolanos). Aquí también cabe aclarar que esta fue una medida temporal y limitada que no aplicó para todas las personas en condición de irregularidad y que tuvo como fecha límite el 31 de enero de 2021.

(4) En lo que respecta a las solicitudes de refugiados, Colombia rechaza la mayoría al exigir pruebas de persecución directa y según cifras del UNHCR, la gran mayoría de las solicitudes de asilo están en trámite. (5) Colombia, Brasil, Perú y Chile muestran experiencias de adaptación de sus medidas a las modificaciones que han tenido los procesos migratorios; no obstante, "en estos países también existieron intentos por implementar medidas restrictivas, a modo de barreras o frenos al ingreso -como la exigencia de pasaporte-, que finalmente revocaron o no llegaron a implementar" (Gandini et al., 2019, p. 19).

Esta aparente cobertura podría ser la enunciación formal de unos derechos que no se materializan. Decir que en Colombia los migrantes tienen derecho al trabajo es una afirmación muy discutible; aunque la legislación así lo promulgue, la realidad de estas poblaciones frente a las opciones de trabajo no podría dar contenido a una aseveración que solo funciona en términos de propaganda. Esto se puede soportar en el estudio de pobreza multidimensional del DANE, publicado el 2 de septiembre de $2021^{1}$, en el cual se afirma que el $44.1 \%$ de los hogares donde al menos una persona reporta ser de Venezuela, están en condición de pobreza multidimensional. Esta proporción llegó a $41.5 \%$ en cabeceras y a $61.3 \%$ en centros poblados y rural disperso.

\section{Consideraciones metodológicas: de la etnografia a la netnografia}

El estudio fue pensado como una etnografía que se desarrollaría en los escenarios en los que las prácticas de consumo de las y los migrantes sucedían. No obstante, la pandemia del COVID-19 hizo necesario desarrollar un trabajo de campo no presencial. Así que optamos por la netnografía como opción metodológica que busca hacer interpretación cultural en el marco de los entornos digitales (Kozinets, 2006).

La netnografía es una apuesta metodológica valiosa que permite acceder a los fenómenos sociales a partir de lo que está objetivado en las redes y a través de formas de interacción digital, las cuales tienen vedadas ciertas posibilidades de encuentro, pero que son cómodas, portátiles y que permiten el manejo de un volumen importante de información. Como señala Hine (2011), la etnografía virtual nos permite acercarnos a internet desde una perspectiva local, identificando cómo herramientas digitales que son de uso global se modulan en las prácticas locales. No se trata de la tecnología en sí misma, sino del uso que los grupos hacen de ella; en esto la perspectiva etnográfica es muy valiosa, porque se centra en los significados y prácticas puntuales de grupos humanos con características específicas.

En el caso que nos ocupa, con el fin de conocer cómo sucedían los intercambios y la construcción de redes de migrantes, y cómo era ese consumo nostálgico de productos asociados a la identidad venezolana, rastreamos 15 grupos de Facebook, abiertos por migrantes residentes en Bogotá. Entre 5.000 y 100.000 perfiles siguen estos espacios, de acuerdo con las cifras de la plataforma. Es decir, el grupo (de los que revisamos) que menos seguidores tiene, cuenta con 5.000, y el más posicionado cuenta con cerca de 100.000

1. Disponible en:

https://www.dane.gov.co/files/investigaciones/condiciones_vida/pobreza/2020/cp_pobreza_multidimensional_20.pdf 
seguidores. No anunciaremos los nombres de estas páginas para no generar un señalamiento público (dado que estas páginas son de libre acceso).

Durante los meses de junio y julio de 2020 hicimos un seguimiento a las publicaciones que las y los migrantes "posteaban" en la plataforma y las analizamos en torno a unas categorías que construimos en la experiencia misma de la observación. Estas categorías fueron: 1. Consumo, identidad y nostalgia, 2. Consumos transmigrantes, 3. Redes e integración, 4. Espacios y territorios representados, 5. Alusiones políticas al proceso de migración, 6. Servicios de venezolanos para venezolanos, y 7. Xenofobia y conflictos binacionales. Así, recogimos 126 capturas de pantalla. En este artículo haremos énfasis en los aspectos centrales de lo que encontramos en las categorías 1, 2 y 3 .

Un segundo proceso metodológico consistió en el desarrollo de un grupo de discusión virtual. A partir de la técnica de bola de nieve identificamos 10 migrantes con los que desarrollamos 2 sesiones virtuales de 2 horas cada una. En estas sesiones hablamos sobre las prácticas de consumo en específico. Este segundo encuentro nos permitió conocer la relación de las y los migrantes con la cotidianidad de Bogotá y nos permitió situar el lugar que tiene la nostalgia y la identidad en sus prácticas de consumo, así como la relación que estas tienen con la construcción de redes. Este es el tema central sobre el que versa este artículo.

El tercer y último proceso consistió en la realización de 60 encuestas virtuales a migrantes venezolanos residentes en Bogotá. Si bien este número no permite hablar en nombre de todas y todos los migrantes del hermano país que viven en la ciudad, sí nos permitió mapear ciertas tendencias y contrastar los datos obtenidos en la observación $\mathrm{y}$ en los grupos de discusión. Veamos ahora los hallazgos de la investigación en lo relacionado a la relación entre consumo y fortalecimiento de redes de migrantes.

\section{Hallazgos}

Remesas y redes de intercambio de dinero

Un escenario en el que se hacen evidentes las relaciones transmigrantes es el de las remesas y su impacto en las economías. En este proceso, que obedece al desarrollo de un servicio (consumo) financiero en el plano de lo informal e incluso de lo legal, se producen relaciones económicas que a su vez suponen redes de intercambio cultural y de recursos.

Los transmigrantes, quienes crean diferentes estrategias y escenarios (cada vez más de carácter informal) envían dinero a su país de origen y con ello tienen cierto grado de injerencia en la economía del acá y del allá, de tal suerte que países como Venezuela pueden tener, a nivel macro social, como un renglón importante de su economía, el dinero que los emigrantes envían a sus familias. Todo esto solo es posible gracias a la existencia de unas redes transnacionales de intercambio que mantienen una circulación de capitales, información y experiencias más allá del margen de la nación.

Según Maldonadoy Flores (2021) del CEMLA (Centro de Estudios Monetarios Latinoamericanos), antes de la pandemia, las remesas representaban el 10\% del PIB de Venezuela. Allí se encontró que el $32.4 \%$ de los encuestados manifiesta que las remesas son su principal fuente de ingreso, asî como el 50.4\% manifestó que las remesas recibidas aportan en más de un hogar; es decir, que el dinero recibido se distribuye en varios hogares. Los países de los que más entra dinero al país bolivariano son Estados Unidos y España. A su vez, el estudio mostró que el 95\% de los encuestados manifiesta usar el dinero en consumo de abastecimiento y salud.

Colombia es un país que tradicionalmente ha sido receptor de remesas. Según la revista Dinero, “Colombia en el año 2004 ocupó el décimo lugar en el mundo como país receptor de remesas y el segundo puesto dentro de los países latinoamericanos y el Caribe después de México”. Entre 2007 y 2008, Colombia ocupó el primer puesto en los países que envían remesas desde España con la cifra de 15.453 millones de euros.

Ahora, con la llegada de ciudadanos venezolanos, el país conoce la otra cara del fenómeno. La revista Dinero, en su edición del 18 de abril de 2019, mostró que el giro de remesas por vía oficial a Venezuela ha decrecido en Colombia. Según el informe de egreso de remesas del Banco de la República, desde Colombia se enviaron a Venezuela 120.000 dólares en 2020, y en el primer trimestre de 2021 el dato fue de 50.000 dólares. Este flujo de remesas por vía legal es solo una parte del fenómeno. En el caso de los migrantes venezolanos en Estados Unidos o en España, demuestran Maldonado y Flores (2021), la principal vía para enviar dinero son las transferencias Zelle 
(Wells Fargo Online), que operan con fluidez en estos países, en particular en Estados Unidos. En cambio en Colombia, por la cercanía entre los dos países y por la informalidad que permea todos los aspectos de la vida económica, las remesas viajan por otros caminos menos institucionalizados. Por eso decrece el dinero que se envía por vía legal y se fortalece un sistema (red) de intercambio de dinero entre particulares.

Son los canales informales, las casas de cambio online y offline, las que hacen, a través de una red informal de circulación del dinero, que las y los migrantes puedan enviar dinero a sus familias. Este consumo de un servicio financiero, desarrollado en el marco de la informalidad, e incluso de la ilegalidad, teje relaciones transnacionales subterráneas, que nos plantean la necesidad de pensar la migración más allá de las lógicas de lo nacional, en cuanto las redes de intercambio de recursos trascienden las fronteras nacionales. Todo un entramado subrepticio de relaciones entre particulares hace que el dinero llegue de Colombia a Venezuela generando un fenómeno que desborda la regulación de los dos Estados.

En la observación netnográfica que hicimos en los quince espacios virtuales de Facebook encontramos con mucha fuerza la operación de las casas de cambio informales. Son emprendimientos que se ofrecen vía electrónica y que les permiten a las y los migrantes enviar dinero evitando los impuestos y optimizando la ganancia que les deja la devaluación del bolivar. Esta forma de intercambio es acorde a tendencias contemporáneas de consumo colaborativo, en cuanto un consumidor de un banco presta su filiación al mismo para la circulación de dinero. Técnicamente es un favor que se presta entre amigos, pero que se convierte en un emprendimiento informal que puede ser el sustento de muchas familias y que genera relaciones laborales y economías solidarias, pero también puede generar defraudaciones e ilícitos.

Reconocimos en la indagación diferentes maneras en las que se da este intercambio. Las más representativas son las dos siguientes: en la primera un usuario tiene una cuenta con Colombia y otra en Venezuela. El cliente le consigna acá y él hace el traslado, siguiendo la normatividad, pero generando menos gastos que los que tendría un ciudadano que envía la remesa por la vía legal. En la segunda, se envía el dinero a alguien que está en la frontera y esta persona cambia la divisa, cruza la frontera y entrega el dinero. Esta red de distribución informal de efectivo hace posible unas relaciones entre las y los migrantes que están en Bogotá, por poner un ejemplo, y los familiares que están en los diferentes territorios de Venezuela. En algunos casos, el intercambio se hace aún más deslocalizado a través de internet, cuando se emplean empresas de cambio que están en una ciudad diferente a la que vive la persona que quiere enviar el dinero. Vimos el caso de una de ellas que está ubicada en Medellín y sirve de intermediario para que las y los migrantes residentes en Bogotá o en Lima envien dinero a sus familias en el país bolivariano. Esta sería entonces una primera relación entre el consumo de un servicio financiero y la creación de redes informales de circulación de dinero y de producción del valor.

Consumos transmigrantes como un escenario con potencial para la construcción de redes

Existen otros consumos que dan cuenta de dinámicas transnacionales y de redes de relaciones de intercambio entre migrantes. Sistemas de pago como Paypal, entre otros sistemas de transferencias internacionales, hacen posible comerciar productos básicos más allá de las fronteras nacionales. En la observación en los espacios virtuales en los que trabajamos encontramos la venta de productos básicos de alimentación y de servicios como serenatas de mariachis y shows sexuales, los cuales se ofrecían desde Venezuela, para venezolanos en el exterior. La siguiente imagen (Figura 2), recabada en el proceso de observación netnográfica, nos permite ejemplificar este fenómeno:

Figura 2. Oferta de servicios musicales a nivel transnacional

Amigo venezolano en el exilio $\oplus$, un saludo cordial y cariñoso desde Mérida Venezuela Puedes darle un regalo musical a tus seres queridos show bailable (hora loca) y el mas completo y grande "Mariachi Garibaldi de Mérida "DE MI TIERRA" a sus gratas ordenes.!! Amenizamos: cumpleaños, grados, 15 años, agasajos, grados, bienvenidas, paraduras, actos fúnebres y cualquier evento social. Puedes seguirnos en twitter $e$ instagram "mgaribaldi 2017" y facebook

"https://www.facebook.com/groups/1753765668273096/" TLF o WHATSAPP:+584147472973/+584147448222/+584163767719/+584124 707696!!!

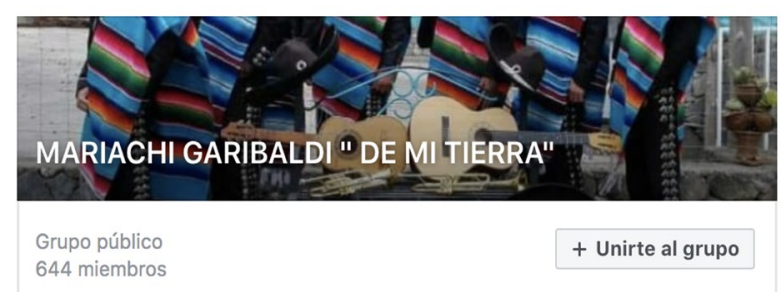

Fuente: archivo netnográfico del equipo de investigación. 
En los espacios de Facebook que observamos encontramos el caso de empresas que ofrecían la venta de productos de primer nivel, para ser consumidos en Venezuela, que eran pagados desde cualquier parte del mundo. El mensaje comercial iba dirigido "a venezolanos en el exterior”. Se ofrecían paquetes de comida y productos básicos de aseo, para compradores en todo el mundo que quisieran enviar estos productos como ayuda a su familia en Venezuela. Al ser posible que un comprador en un territorio cualquiera pueda adquirir productos que no va a usar directamente, pero que sí va a enviar a un tercero en algún contexto específico de Venezuela, se abren diferentes relaciones comerciales, políticas, culturales y quizás con el tiempo jurídicas y por qué no, políticas.

Es aún muy pronto para afirmarlo y la futurología suele ser problemática en las ciencias sociales, por ello lo dejaremos apenas enunciado como una hipótesis a corroborar en futuras investigaciones: los intercambios informales, virtuales y deslocalizados, pueden potenciar relaciones transmigratorias (más allá del simple intercambio de dinero por productos) y plantear posibilidades de intercambio que hagan más porosa la acción de las fronteras nacionales. Consumir es más que un acto mecánico por el cual las personas satisfacen sus necesidades por medio de la adquisición de servicios y productos. En el consumo se producen relaciones, se reelaboran significados y se expresan los capitales. De esta manera, el desarrollo de consumos transmigrantes, o de la posibilidad que tienen y tendrán los migrantes de consumir de manera simultánea en el contexto de origen y en el contexto de recepción, hará que ese enunciado de "amigo venezolano en el exterior", genere una nueva categoría de consumidores y plantee otros juegos materiales y simbólicos que llevarán a pensar en consumidores deslocalizados con exigencias deslocalizadas y expresiones deslocalizadas.

La construcción de redes sociales digitales y su lugar en el fenómeno migratorio

En la encuesta que realizamos a 60 migrantes encontramos que el 34\% manifestó tener familia venezolana en Bogotá antes de haber decidido migrar a esta ciudad. Así mismo, el 36\% dijo tener amigos venezolanos residiendo en esta ciudad.
De igual manera, el 70\% ya contaba con una red de apoyo de personas venezolanas cuando llegó a instalarse en la capital de Colombia. Nuestro interés consistía en enfocarnos de manera especial en las redes transnacionales de migrantes y en el lugar que en ellas ocupaba el consumo como proceso social central en la integración de los y las migrantes a los contextos de recepción. Como señala Zenteno (2000), estas redes son órganos reguladores del acceso a la información y a las oportunidades de empleo (Massey y Parrado, 1997; Portes, 1995), y constituyen una palanca para que la migración suceda cada vez menos en virtud de causas estrictamente económicas (Massey y Parrado, 1997).

Es importante resaltar que estas redes pueden operar de manera personal o virtual. Los espacios virtuales se han convertido en herramientas para afianzar relaciones entre migrantes, para hacer circular información, contactos e intercambios de manera efectiva y rápida. En nuestra investigación indagamos sobre el lugar de las redes sociales en el proceso de integración a la vida de la ciudad. En la encuesta encontramos que el 46\% dice usar frecuentemente Facebook para enterarse de los temas que tienen relevancia para los y las migrantes, mientras el $30 \%$ lo hace a través de Instagram, 24\% lo hace en periódicos locales. Ninguno dijo usar Twitter, LinkedIn ni YouTube. Además, mostraron una actitud mayoritariamente positiva cuando en una pregunta abierta les indagamos por las ventajas y desventajas de unirse a los grupos de Facebook de migrantes.

Las bondades de estos espacios, según lo que encontramos en esta indagación, son percibidas por los y las migrantes de acuerdo a la posibilidad de tener información sobre la diáspora venezolana en Bogotá; la posibilidad de acceder a productos de origen (mayoritariamente de comida) que son ofrecidos virtualmente, la posibilidad de conocer gente y de enterarse de ofertas de empleo para venezolanos. Por desventajas, en menor medida, señalaron: la exposición de la identidad, la saturación de conversaciones inútiles y la existencia de personas colombianas que usaban estos espacios para ejercer la violencia xenófoba.

El trabajo en los grupos de discusión nos permitió matizar y complementar estos hallazgos. Allí los participantes nos señalaron 
la importancia de estos espacios virtuales en el momento de la llegada a la ciudad. No obstante, algunos dijeron que conforme iban construyendo redes en el mundo offline, la participación en estos escenarios disminuyó. Algunos señalaban que con el tiempo habían encontrado que más que un espíritu altruista, lo que motivaba muchas de las interacciones que tenían lugar en estos escenarios virtuales era el interés particular de algunas personas que en ciertas ocasiones sacaban provecho comercial al tener tantos seguidores. Al respecto, un participante del grupo de discusión señaló:

Creo que fui uno de los principales, de las primeras personas que participó en ese grupo de Facebook. Te estoy hablando del año 2014, más o menos; cuando decidí ingresar a ese grupo no habian más de 500 personas en él; y en ese momento, cuando estaba tomando la decisión de viajar hacia Colombia, realmente sí me funcionó mucho porque tenía muchas dudas acerca de cómo se manejaba la ciudad, cómo se manejaba el país. Entonces digamos que sí tuve una experiencia en aquel momento buena de información de las personas que ya estaban ubicadas acá en Colombia y en Bogotá, particularmente para guiarme un poco de cómo está distribuida la ciudad: norte, sur, oriente, occidente. Todo ese tipo de información la obtuve a través de esa cuenta que particularmente que se llama venezolanos en Bogotá, te estoy hablando del año 2014. (Participante del grupo de discusión)

Otra de las participantes nos mostró cómo fue creciendo su desconfianza en estos grupos y cómo fue creando nuevas relaciones con personas residentes en Bogotá, tanto migrantes como no migrantes. En su explicación se entrevé la importancia del consumo en la construcción de redes sociales, tema que abordaremos más adelante.

“...mira, te soy sincera, grupos, en Instagram, yo he encontrado 12,14 , cuentas con diferentes variantes, con guion al piso, con plural, singular, números y pare de contar. En Facebook, hay otros 8 o 9 grupos que yo conozco, pero te soy sincera, no confío en esos grupos. Yo he preferido comprar a venezolanos, mujeres, hombres, lo que sea, pero que yo primero conozco. Por ejemplo la que me vende la masa de pastelitos la conocí a través de un grupo de mamás emigrantes y a ella le compré la masa de pastelitos” (...) los tequeños yo estoy ahora ya me mude, ahora estamos pa' Suba, pero los tequeños y los compro al muchacho que vive en las Américas y desde las Américas me las traen la Suba con malta polar; y prefiero pagar el viaje, el envío, lo que sea, con tal de comprarle, pero yo no confío en redes sociales porque ya nos pasaron unos chascos como dicen aquí de suplantaciones y robos y de ahí yo no compro nada si no es que no lo conocí primero. (Participante del grupo de discusión)

En nuestra propia experiencia como observadores de estos espacios virtuales encontramos una gran carga de contenido y una riqueza de prácticas sociales y de consumo. Como ya se dijo, estos grupos tienen una gran acogida y un número importante de seguidores. Así mismo, tienen un volumen significativo de publicaciones, en las que hay un protagonismo fuerte de la oferta de productos de diversa indole (comida, electrodomésticos de segunda mano, bicicletas, ropa, etc.), la información sobre posibilidades de empleo (mayoritariamente informal) y la información sobre procedimientos administrativos y políticos que involucran a los y las migrantes tanto en el contexto de origen como en el contexto receptor. Todo esto desde un discurso con connotaciones de identidad nacional y nostalgia.

\section{Consumo y redes sociales en el contexto de la transmigración}

Convenimos con Torres Matus (2012) en que el consumo puede ser una motivación que genere el proceso migratorio. En el caso que nos interesa, la migración de ciudadanos venezolanos a Colombia, y en particular a Bogotá, en muchos casos, fue motivada por la imposibilidad de abastecimiento que las personas tienen hoy en Venezuela gracias a la crisis humanitaria que se vive en dicho país. Si bien se mantienen muchas plazas de trabajo, los salarios, en relación con la inflación, no permiten que muchos ciudadanos puedan tener un consumo de abastecimiento mínimo. Por supuesto, el consumo no es la única demanda que motiva la migración, pero tampoco es simplemente un efecto, menos en el marco global de una sociedad de consumo.

Esto supone que al poder consumir, las y los migrantes se incluyen, de cierta manera, por vía del mercado. Ahora bien, esta integración también puede darse a través del Estado cuando 
este reconoce a las y los migrantes y se les permite ejercer ciertos derechos civiles. Esta doble inclusión, vía Estado y vía mercado, nos muestra temporalidades distintas. Es probable que en muchos contextos las personas puedan conseguir un trabajo y consumir, más rápido de lo que pueden obtener la ciudadanía y hacer ejercicio pleno de los diferentes derechos. O, por el contrario, es posible una situación como la que se ha visto en Colombia, con la llegada de los ciudadanos venezolanos que obtienen ciertos derechos gracias a una legislación incluyente, pero que en términos materiales están excluidos de la dinámica económica de la sociedad. Esta perspectiva se retoma de Torres Matus, quien señala:

Nuestra atención se ubica en la intersección entre los derechos económicos y sociales, por un lado y los derechos políticos por otro; éstos últimos son vistos como la culminación de un proceso total de integración de un migrante a la sociedad receptora, ya que es un ciudadano con plenos derechos y deberes. Los migrantes, en su proceso de integración a un país lo hacen principalmente a través del sistema económico y su estructura, como asalariado en el mejor de los escenarios, donde la inserción laboral es fundamental para su largo proceso de negociaciones sociales y culturales, de valores y de visiones en la sociedad receptora. A medida que ingresa al sistema económico y al sistema laboral del país receptor, puede ejercer sus derechos a través del acceso a ciertos servicios y productos, también a ciertos mundos, aspiraciones, ideas, intereses que son compartidos por un amplio grupo de personas. (Torres Matus, 2012, p. 214)

Otra perspectiva desde la que se analiza el lugar del consumo en los procesos migratorios tiene que ver con las ganancias que las y los migrantes generan para el contexto de recepción en cuanto consumidores (Gómez, 2010; Caamaño, 2010). La llegada de una nueva colonia de migrantes genera nuevos consumos que diversifican la oferta, mueven la economía y terminan generando ganancias. En el caso de Bogotá, esta afirmación debe revisarse con datos empíricos, pues dadas las precarias condiciones de un buen número de migrantes, es posible que estos nuevos consumos aún no se puedan considerar verdaderos motores de la economía local. No obstante, a futuro es posible que exista una industria de productos y servicios para migrantes venezolanos, lo que, siguiendo la argumentación que hemos desarrollado a lo largo del artículo, generaría una inclusión vía mercado y expresaría cierta integración colectiva de los migrantes a la vida económica y cultural de la ciudad.

\section{Reflexiones finales}

En este apartado final haremos una síntesis de las ideas principales abordadas a lo largo del artículo. En primer lugar, consideramos importante resituar el consumo en los estudios sobre los procesos migratorios, dado que no es un simple efecto de la producción, o mejor, de la inclusión de las y los migrantes al sistema productivo en el contexto receptor, sino que puede considerarse como un proceso social que opera como un potenciador de redes, un escenario para movilizar símbolos, y una motivación para quienes deciden dejar su territorio de origen, así como un escenario para construir y mantener relaciones transnacionales entre las y los migrantes. De esta forma, consideramos que nuevas investigaciones pueden hacer más énfasis en el lugar que tienen las dinámicas de consumo en la manera en que se configuran los escenarios en los que se mueven los transmigrantes.

En segundo lugar, queremos señalar que la migración de población venezolana a Colombia, y en particular a Bogotá, es parte de una dinámica particular entre los dos países, los cuales en diferentes momentos de su historia han observado flujos migratorios de ida y vuelta. Gracias a este fenómeno y a unas prácticas culturales compartidas (musicales, alimenticias, etc.), este proceso observa algunas características especiales. Es decir, es distinto pensar la llegada de la migración boliviana a Buenos Aires (o de los mexicanos a Estados Unidos) a la llegada de los venezolanos al territorio nacional, dado que en los primeros casos las diferencias étnicas y lingüísticas hacen que los procesos de integración sean más "evidentes". Un indicador de esto que estamos planteando está en las cifras sobre el asentamiento de la población migrante en el territorio de la ciudad de Bogotá. Como mostramos en el mapa elaborado por el equipo con base en los datos oficiales del DANE, la población venezolana se ubica a lo largo y ancho de la ciudad, conviviendo con las comunidades receptoras sin agruparse en concentraciones específicas de migrantes.

Por supuesto, todos los procesos 
migratorios tienen matices particulares. En este caso es necesario considerar que Colombia no tiene experiencia como país receptor de migrantes y que la existencia de ciertos referentes compartidos hace posible que se construyan redes binacionales, tanto de trabajo como de ocio, convivencia, etc. Esto no anula la xenofobia, la discriminación ni la defensa de una identidad venezolana, pero sí muestra otros matices entre las y los migrantes y la población receptora.

En tercer lugar, queremos hacer énfasis en lo planteado por Torres Matus (2012), quien propone que en las poblaciones migrantes es posible ver un proceso de integración vía Estado y otro paralelo vía mercado. $\mathrm{El}$ primero nos remite a los procesos jurídicos que los Estados tienen para reconocer a las y los migrantes; este reconocimiento tiene un impacto fundamental, pero no es igual ni sucede al mismo tiempo del proceso de integración que se da en la esfera de la producción y el consumo. Allî se evidencian algunas tensiones. Es posible que alguien tenga el reconocimiento del Estado, pero no pueda producir ni participar de las dinámicas de consumo. También es posible que alguien no esté reconocido, pero pueda disfrutar, aunque sea en parte, de la oferta del contexto que lo recibe. En Colombia, para las y los migrantes venezolanos, vemos que la existencia de medidas formales que permiten atender personas que entraron incluso de manera irregular, $y$ ofrecerles un paquete reducido de derechos; no obstante, estos gestos gubernamentales no hablan de un proceso de integración. Por vía del mercado, tampoco se integra a las y los migrantes, lo que se evidencia en un mercado casi clandestino de productos que ellos circulan y que se convierten en espacios para construir redes sociales y redes migrantes.

De la misma manera que en el contexto de la producción se crean vínculos y se intercambian capitales, también se puede afirmar que en el consumo se crean vínculos y movilizan redes, lo que en el contexto contemporáneo sucede tanto a nivel online como a nivel offline. Las posibilidades tecnológicas, y en particular las redes sociales, han transformado las dinámicas transmigratorias. Los grupos de Facebook que analizamos son una muestra de ello. En la llegada de la población venezolana a Bogotá, para mucha gente, las redes sociales fueron una guía y una posibilidad de hacer relaciones con otras personas, con la ciudad y con organizaciones "imaginadas", como son los grupos virtuales. Esto no siempre se mantiene en el tiempo, ni sucede siempre de manera satisfactoria, pero estas formas de comunicación y relacionamiento social tienen una injerencia en los matices particulares que tiene la migración hoy, razón por la que deben seguir en el foco de los estudios de procesos migratorios.

Por último, señalamos que la nostalgia adquiere una función estratégica en el consumo desarrollado por las y los migrantes venezolanos en Bogotá. Además, reiteramos la importancia que en esto tiene la comida, como movilizadora de identidad, como posibilidad de diferenciación y como escenario para mantener ciertas prácticas que se desarrollaban en el contexto de origen. El consumo nostálgico es un disparador de emprendimientos y un punto de partida para la construcción de redes sociales. En la Bogotá de las y los migrantes venezolanos esto es un proceso que apenas empieza y que a futuro puede significar una transformación cultural y económica para la ciudad, lo cual, gracias a las dinámicas transnacionales, puede tener un impacto simultáneo en las dos naciones.

\section{Referencias}

Anthias, F. (2006). Género, etnicidad, clase y migración: interseccionalidad y pertenencia translocalizacional. En Rodríguez, P. (Ed.), Feminismos periféricos (pp. 49-68). Granada: Editorial Alhulia.

Berganza Setién, I., y Solórzano Salleres, X. (2019). Límites y retos del Estado Procesos de integración de la comunidad venezolana en Perú. Lima: Universidad Antonio Ruiz de Montoya, Jesuitas Lutheran World Relief, Asociación Encuentros Servicio Jesuita para la Solidaridad.

Blouin, C (Coord.). (2019). Después de la llegada. Realidades de la migración venezolana. Lima: Themis.

Caamaño, C. (2010). Entre arriba y abajo. La experiencia transnacional de la migración costarricense hacia Estados Unidos. San José de Costa Rica: Editorial Universidad de Costa Rica.

Gandini, L., Lozano, F., y Prieto, V. (2019). Crisis y migración de población venezolana. Entre la desprotección y seguridad jurídica en ciudades latinoamericanas. Ciudad de México: UNAM.

Gómez, J. (2010). La Migración Internacional: Teorías y Enfoques, Una Mirada Actual. Semestre Económico, 13(26), 81-99.

González, C. (2021). Estudios sociales del consumo, algu- 
nas propuestas para su reflexión y aplicación metodológica. En Consumo, territorios y sujetos, miradas locales. Bogotá: Editorial Universidad Central.

Hine, C. (2011). Etnografia virtual. Barcelona: Editorial UOC.

Itzigsohn, J., Cabral, C. D., Medina, E. H., \& Vazquez, O. (1999). Mapping Dominican transnationalism: narrow and broad transnational practices. Ethnic and Racial studies, 22(2), 316-339

Kozinets, R. V. (2006). Netnography. Handbook of qualitative research methods in marketing. Cheltenham: Edward Elgar Publishing (pp. 129-142).

Levitt, P., y Gilk, N. (2004). Perspectivas Internacionales Sobre Migración: Conceptuar la Simultaneidad y Desarrollo. Migración y Desarrollo, 3, 60-91. https://doi.org/10.35533/myd.0203.pl.ngs

Narotzky, S. (2004). Antropología económica. Nuevas tendencias, 127-174.

Maldonado, R. y Flores, A. K. (2021). Migración internacional, remesas e inclusión financiera. El caso de Venezuela. Ciudad de México: Centro de Estudios Monetarios Latinoamericanos (CEMLA).

Massey, D. y Parrado, E. (1997). Migración y pequeña empresa. Revista Ciudades, (35), 34-40.

Montenegro M. y García D. (2021). Estudios del consumo un estado de la cuestión en Latinoamérica. En Consumo, territorios y sujetos, miradas locales. Bogotá: Editorial Universidad Central.

Pedone, C. (2005). Tú, siempre jalas a los tuyos. Cadenas y redes migratorias. En La migración ecuatoriana. Transnacionalismo, redes e identidades. Quito: FLACSO Sede Ecuador (pp. 105-143).

Portes, A. (2005). Convergencias Teóricas y Evidencias Empíricas En El Estudio Del Transnacionalismo de Los Inmigrantes. Migración y Desarrollo, Volumen 3, 4, 2-19. https://doi.org/10.35533/ myd.0304.ap

Torres Matus, L. (2012). Los Migrantes Fronterizos como Consumidores de bienes, Servicios e Ideas y sus Implicancias para Chile. Reflexiones Preliminares. Imagonautas, 1(2), 210-226.

Zenteno, R. (2000). Redes Migratorias: ¿Acceso y Oportunidades Para Los Migrantes? En Migración México-Estados Unidos Opciones de política. Ciudad de México: Consejo Nacional de Población. 